\title{
A Rectangular Ring, Open-Ended Monopole Antenna with Two Symmetric Strips for WLAN and WiMAX Applications
}

\author{
Joong-Han Yoon, ${ }^{1}$ Young-Chul Rhee, ${ }^{2}$ and Woo-Su Kim ${ }^{3}$ \\ ${ }^{1}$ Department of Electronic Engineering, Silla University, San 1-1 Gwaebeop-Dong, Sasang-Gu, Busan 617-736, Republic of Korea \\ ${ }^{2}$ Department of Information and Communication Engineering, Kyungnam University, 449 Wolyong-Dong, Masan, \\ Kyungnam 631-701, Republic of Korea \\ ${ }^{3}$ School of Electrical and Computer Engineering, Georgia Institute of Technology, North Avenue, Atlanta, GA 30332, USA
}

Correspondence should be addressed to Woo-Su Kim; wkim84@mail.gatech.edu

Received 13 November 2012; Accepted 21 January 2013

Academic Editor: Stefano Selleri

Copyright (c) 2013 Joong-Han Yoon et al. This is an open access article distributed under the Creative Commons Attribution License, which permits unrestricted use, distribution, and reproduction in any medium, provided the original work is properly cited.

\begin{abstract}
A triple-band rectangular ring, open-ended monopole antenna with symmetric $L$ strips for wireless local area network (WLAN)/Worldwide Interoperability of Microwave Access (WiMAX) applications is proposed. The proposed antenna consists of two symmetric folded arms and $L$ strips. Based on the concept, a prototype of the proposed triple antenna has been designed, fabricated, and tested. The numerical and experimental results demonstrated that the proposed antenna satisfied the $-10 \mathrm{~dB}$ impedance bandwidth requirement while simultaneously covering the WLAN and WiMAX bands. Furthermore, this paper presented and discussed the 2D radiation patterns and 3D gains according to the results of the experiment. The proposed antenna's peak gain varied between 2.17 and $4.93 \mathrm{dBi}$, and its average gain varied between -2.97 and $-0.53 \mathrm{dBi}$.
\end{abstract}

\section{Introduction}

The recent increasing demand for antennas with multiband operation capabilities in modern communication systems has attracted public attention. Likewise, the ability to integrate more than one communication standard into a single system has become a most sought-after feature of a modern wireless communication device. In the last few years, wireless local area networks (WLANs) with connections to portable terminals, such as personal digital assistants (PDAs), notebooks or laptop computers, smart phones, and other similar equipment, have been governed through the standardization of frequency bands that are defined by various standard protocols, namely, IEEE $802.11 \mathrm{a}(5.15-5.35 \mathrm{GHz}$ and $5.725-5.85 \mathrm{GHz})$ and $802.11 \mathrm{a} / \mathrm{g}(2.4-2.484 \mathrm{GHz})$. Furthermore, Worldwide Interoperability of Microwave Access (WiMAX) has been deployed to provide mobile broadband Internet services with large coverage areas in many countries. Recently, WiMAX has primarily allocated three different frequency bands (WiMAX: 2.5-2.69, 3.3-3.7, and 5.25-5.85 GHz) $[1,2]$.
In the near future, these consumer electronic devices will be capable of integrating multiple frequency bands (WLAN, WiMAX, etc.) into one single system. Among the key components of these devices, the antenna plays an important role in determining the RF performance of the end product. The antenna used in these devices is required to operate at different frequency bands or broadband in WLAN and WiMAX systems. Furthermore, many monopole antennas with different structure have been reported such as the Gshaped monopole [3], the rectangular ring monopole [4], the C-shaped monopole [5], the W-shaped monopole [6], the Y-shaped monopole [7], F-shaped [8], double T-shaped [9], and double S-shaped [10]. However, these antennas can only cover one application. Thus, to make multiband and wideband WLAN/WiMAX antennas, studies on WLAN/WiMAX for triple-band applications have been made. In particular, the rectangular ring, monopole antenna for WLAN/WiMAX bands is proposed [3-7].

The dual rectangular ring, printed CPW-fed monopole antenna with inverted T-shaped strip [11], the rectangular 


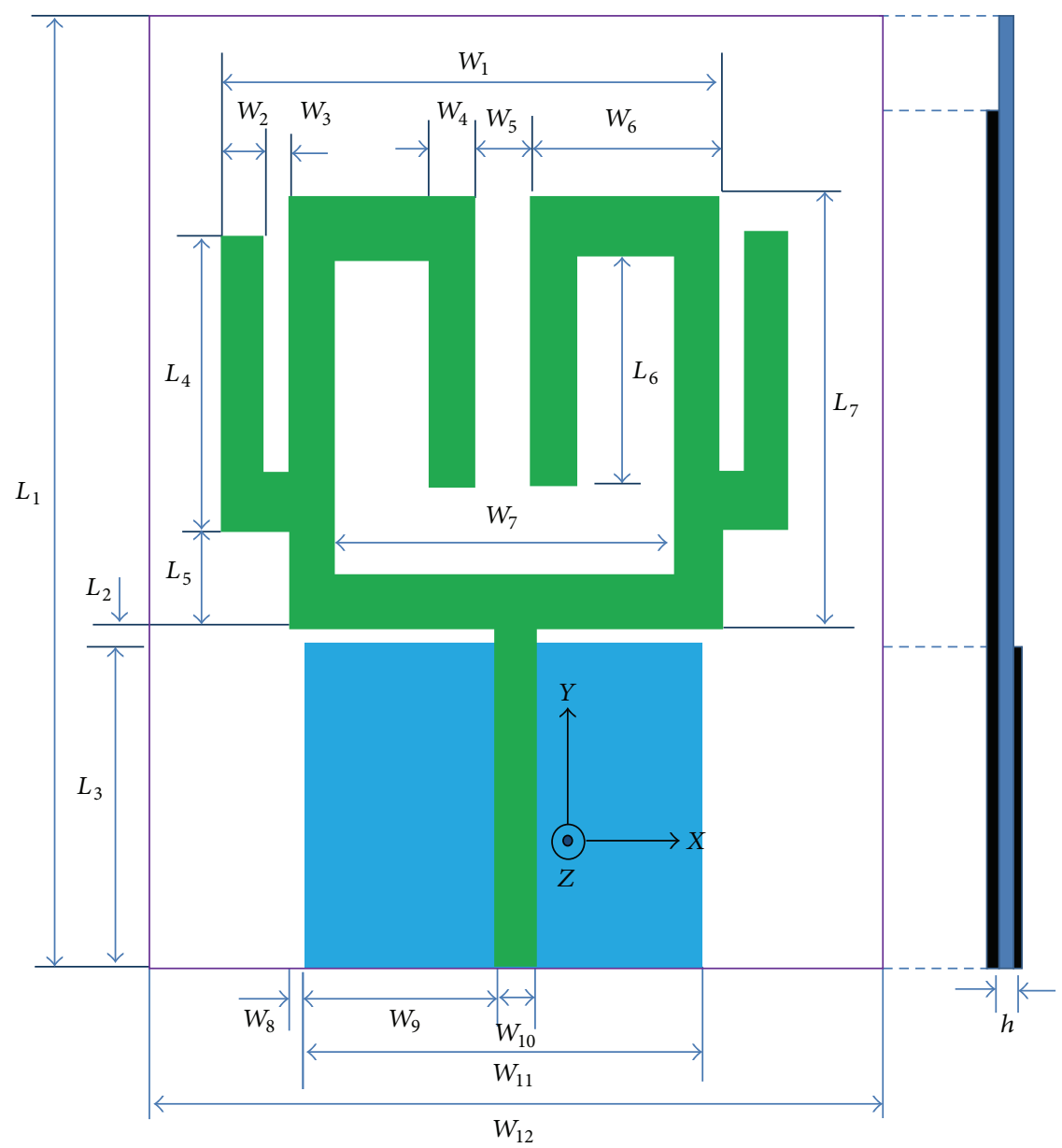

FIGURE 1: Configuration of the rectangular ring, open-ended monopole antenna with two symmetric folded arms and two symmetric $L$ strips.

ring, monopole antenna with a straight strip and a meandered strip [12], and the rectangular ring, monopole antenna with symmetric $L$ strips [13] have been suggested. These antennas are designed and fabricated at a substrate with relative permittivity of $3.5,2.65$, and 2.65 , respectively. These proposed antennas are made of expensive materials, compared to conventional FR4 materials. Likewise, the dual rectangular ring with open-ended CPW-fed monopole antenna [14] is introduced. The total size of the proposed antenna is quite large. Next, the square ring, monopole antenna with a vertical and $L$-shaped strip [15] is proposed. The $L$ strip is located on the bottom side and is connected to the square ring through a hole. This proposed antenna has a complicated structure because a hole has to be made.

In this paper, a rectangular ring, open-ended monopole antenna with two symmetric folded arms and $L$ strips for WLAN and WiMAX band applications was designed. The proposed antenna was fabricated with the use of a conventional FR4 material that is often used to make printed circuit boards and is easy to manufacture. By properly selecting the dimensions of the proposed antenna, good triple broadband bandwidth capabilities, and suitable radiation characteristics for two multiband wireless communication systems, such as WLAN (2.4-2.483 GHz, 5.15-5.85 GHz) and
WiMAX (2.5-2.69, 3.3-3.7, and 5.25-5.85 GHz) operations, this study's goals can be achieved. The antenna configuration and simulated data, as well as the constructed prototype and measured data, will be carefully examined and discussed in the succeeding sections.

\section{Antenna Design}

Figure 1 shows the specific configuration designed for the WLAN/WiMAX printed monopole antenna, which consists of two symmetric folded arms and $L$ strips. The total sizes of the substrate and the ground plane of the proposed antenna that was used in this study were $30.0 \times 40.0 \mathrm{~mm}\left(W_{12} \times L_{1}\right)$ and $19.0 \times 17.2 \mathrm{~mm}\left(W_{11} \times L_{3}\right)$, respectively. The radiating element was placed on the same side as the feeding strip line, and the ground plane was placed on the other side of the substrate. The proposed antenna is fabricated on an inexpensive FR4 substrate with a relative permittivity of 4.4 and a thickness of $1.0 \mathrm{~mm}$.

The proposed antenna had rectangular ring, open-ended strip lines that have a uniform width $\left(W_{2}=W_{4}=W_{10}, 2 \mathrm{~mm}\right)$ for design convenience. In this design, the rectangular ring, open-ended antenna with symmetric, folded arms was resonant for $2.4 \mathrm{GHz} / 2.5 \mathrm{GHz}$ WiMAX bands. Two symmetric, 


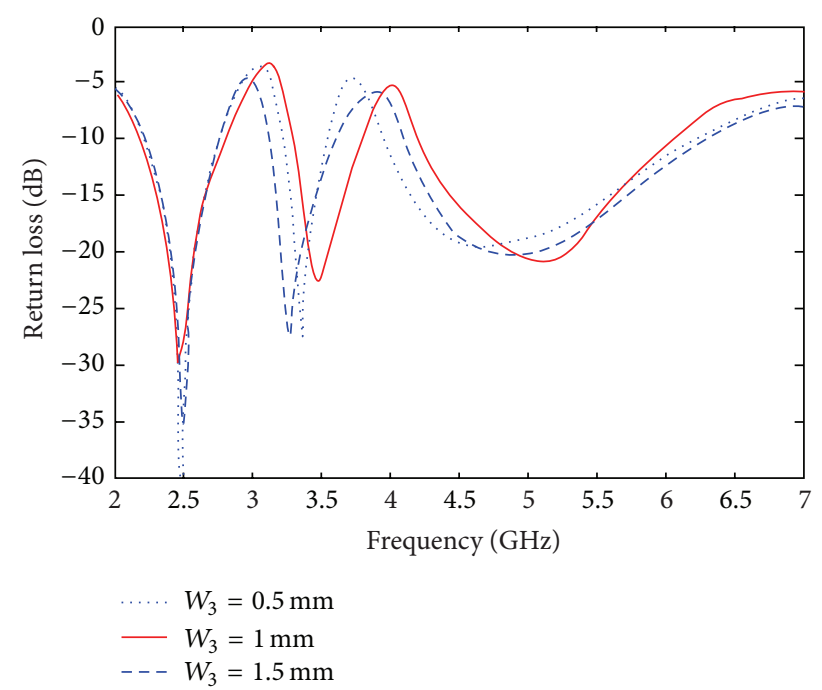

FIGURE 2: Simulated return loss of the proposed antenna with different values of gap width between the rectangular ring, openended antenna and the $L$ strip $\left(W_{3}\right)$. (Other parameters: $L_{1}=$ $40.0 \mathrm{~mm} ; L_{2}=1.8 \mathrm{~mm} ; L_{3}=17.2 \mathrm{~mm} ; L_{4}=12.5 \mathrm{~mm} ; L_{5}=$ $3.0 \mathrm{~mm} ; L_{6}=9.0 \mathrm{~mm} ; L_{7}=16.0 \mathrm{~mm} ; W_{1}=27.0 \mathrm{~mm} ; W_{2}=2.0 \mathrm{~mm}$; $W_{4}=2.0 \mathrm{~mm} ; W_{5}=3.0 \mathrm{~mm} ; W_{6}=9.0 \mathrm{~mm} ; W_{7}=17.0 \mathrm{~mm} ;$ $W_{8}=1.0 \mathrm{~mm} ; W_{9}=8.5 \mathrm{~mm} ; W_{10}=2.0 \mathrm{~mm} ; W_{11}=19.0 \mathrm{~mm} ;$ and $W_{12}=30.0 \mathrm{~mm}$.)

folded arms are attached to the end of the rectangular ring, open-ended antenna. To obtain good impedance matching and wide bandwidth for 3.5 and $5 \mathrm{GHz}$ operating frequencies, we introduced the two symmetric $L$ strips, $3.0 \times 12.5 \mathrm{~mm}^{2}$, $\left(W_{2}+W_{3}\right) \times L_{4}$. Two symmetric $L$ strips are attached to the side of the rectangular ring, open-ended antenna. A $50 \Omega$ microstrip feed line, $W_{10}=2 \mathrm{~mm}$, is used for centrally feeding the antenna from the bottom edge of the symmetrical rectangular ring, open-ended antenna. To obtain the optimal parameters (lines and lengths) of the proposed antenna for WLAN and WiMAX applications, HFSS [16], a full-wave commercial EM software that is capable of simulating a finite substrate and a finite ground structure was used. The length and width of the two symmetric, folded arms and $L$ strips control the input of the proposed antenna.

2.1. Effect of the Two Symmetric, Folded Arms $\left(W_{3}\right)$. Figure 2 illustrates the return loss for the different values of gap width between the rectangular ring, open-ended antenna and the $L$ strip $\left(W_{3}\right)$. It can be seen in the figure that the impedance bandwidth and characteristics of the return loss slightly changed when $W_{3}$ changed from 0.5 to $1.5 \mathrm{~mm}$ in the 3.5 and $5 \mathrm{GHz}$ bands. It can also be seen in the figure, however, that the impedance bandwidth and characteristics of the return loss did not change in the $2.4 \mathrm{GHz}$ and $2.5 \mathrm{GHz}$ bands. This implied that gap width is affected by the characteristics of the return loss in $3.5 \mathrm{GHz}$ and $5 \mathrm{GHz}$ bands. To design a good triple-band WLAN/WiMAX operation, $W_{3}$ was set at $1.0 \mathrm{~mm}$.

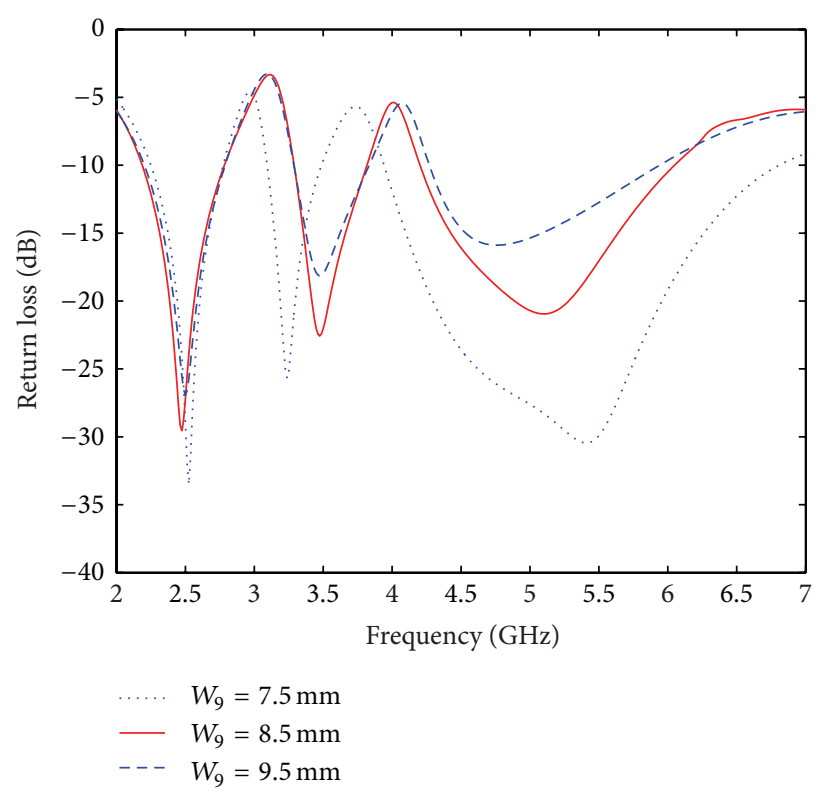

FIGURE 3: Simulated return loss of the proposed antenna with different values of the ground plane $\left(W_{9}\right)$. (Other parameters: $L_{1}=$ $40.0 \mathrm{~mm} ; L_{2}=1.8 \mathrm{~mm} ; L_{3}=17.2 \mathrm{~mm} ; L_{4}=12.5 \mathrm{~mm} ; L_{5}=$ $3.0 \mathrm{~mm} ; L_{6}=9.0 \mathrm{~mm} ; L_{7}=16.0 \mathrm{~mm} ; W_{1}=27.0 \mathrm{~mm} ; W_{2}=2.0 \mathrm{~mm}$; $W_{3}=1.0 \mathrm{~mm} ; W_{4}=2.0 \mathrm{~mm} ; W_{5}=3.0 \mathrm{~mm} ; W_{6}=9.0 \mathrm{~mm} ;$ $W_{7}=17.0 \mathrm{~mm} ; W_{8}=1.0 \mathrm{~mm} ; W_{10}=2.0 \mathrm{~mm} ; W_{11}=19.0 \mathrm{~mm} ;$ and $W_{12}=30.0 \mathrm{~mm}$.)

2.2. Effect of the Ground Plane $\left(W_{9}\right)$. Figure 3 illustrates the return loss for the different values of the ground plane $\left(W_{9}\right)$. It can be seen in the figure that the impedance bandwidth and characteristics of the return loss did not change when $W_{9}$ changed from 7.5 to $9.5 \mathrm{~mm}$ in the $2.4 \mathrm{GHz}$ WLAN and $2.5 \mathrm{GHz}$ WiMAX bands. It can also be seen in the figure, however, that the impedance bandwidth and characteristics of the return loss greatly changed in the $3.5 \mathrm{GHz}$ and $5 \mathrm{GHz}$ bands. In particular, impedance bandwidth and characteristics of the return loss improved in the $5 \mathrm{GHz}$ band, but required frequency bands deviated in the $3.5 \mathrm{GHz}$ band when $W_{9}$ was $9.5 \mathrm{~mm}$. To design a good triple-band WLAN/WiMAX operation, $W_{9}$ was set at $8.5 \mathrm{~mm}$.

\subsection{Effect of Gap Width between the Rectangular Ring,} Open-Ended Antenna and the Ground Plane $\left(L_{2}\right)$. Figure 4 illustrates the return loss for the different values of the gap width between the rectangular ring, open-ended antenna and the ground plane $\left(L_{2}\right)$. It can be seen in the figure that the impedance bandwidth and characteristics of the return loss slightly changed when $W_{3}$ changed from 1.6 to $2.0 \mathrm{~mm}$ in the required frequency bands. This implied that the gap width is significantly affected by the characteristics of the return loss in the required frequency bands. To design a good triple-band WLAN/WiMAX operation, $L_{2}$ was set at $1.8 \mathrm{~mm}$.

2.4. Effect of Two Symmetric $L$ Strips $\left(L_{4}\right)$. Figure 5 illustrates the return loss for the different values of $L$ strips $\left(L_{4}\right)$. It can be seen in the figure that the impedance bandwidth 


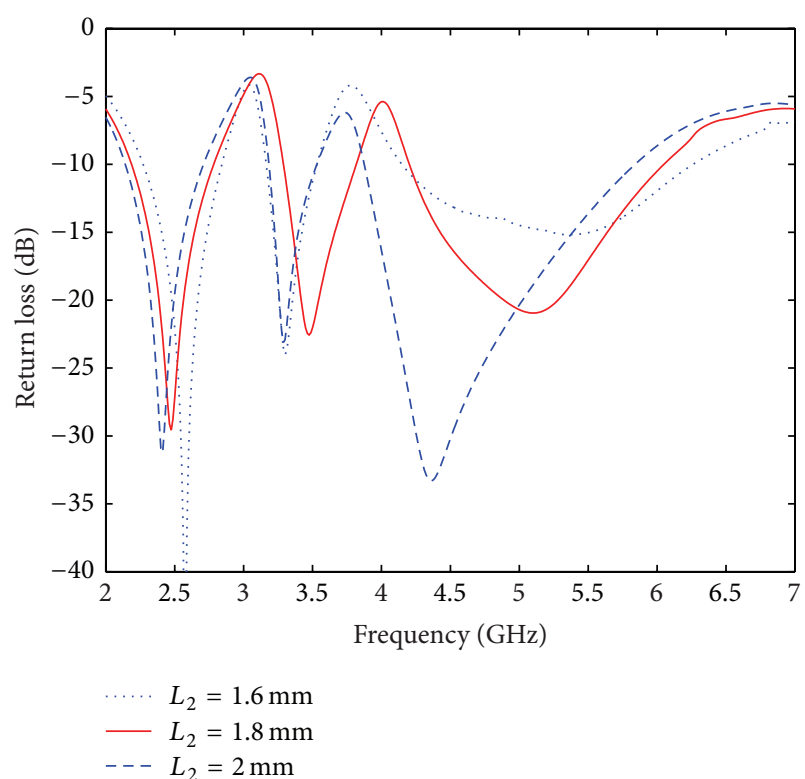

FIGURE 4: Simulated return loss of the proposed antenna with different values of gap length between the rectangular ring, openended antenna and the ground plane $\left(L_{2}\right)$. (Other parameters: $L_{1}=$ $40.0 \mathrm{~mm} ; L_{3}=17.2 \mathrm{~mm} ; L_{4}=12.5 \mathrm{~mm} ; L_{5}=3.0 \mathrm{~mm} ; L_{6}=$ $9.0 \mathrm{~mm} ; L_{7}=16.0 \mathrm{~mm} ; W_{1}=27.0 \mathrm{~mm} ; W_{2}=2.0 \mathrm{~mm} ; W_{3}=$ $1.0 \mathrm{~mm} ; W_{4}=2.0 \mathrm{~mm} ; W_{5}=3.0 \mathrm{~mm} ; W_{6}=9.0 \mathrm{~mm} ; W_{7}=17.0 \mathrm{~mm} ;$ $W_{8}=1.0 \mathrm{~mm} ; W_{9}=8.5 \mathrm{~mm} ; W_{10}=2.0 \mathrm{~mm} ; W_{11}=19.0 \mathrm{~mm}$; and $W_{12}=30.0 \mathrm{~mm}$.)

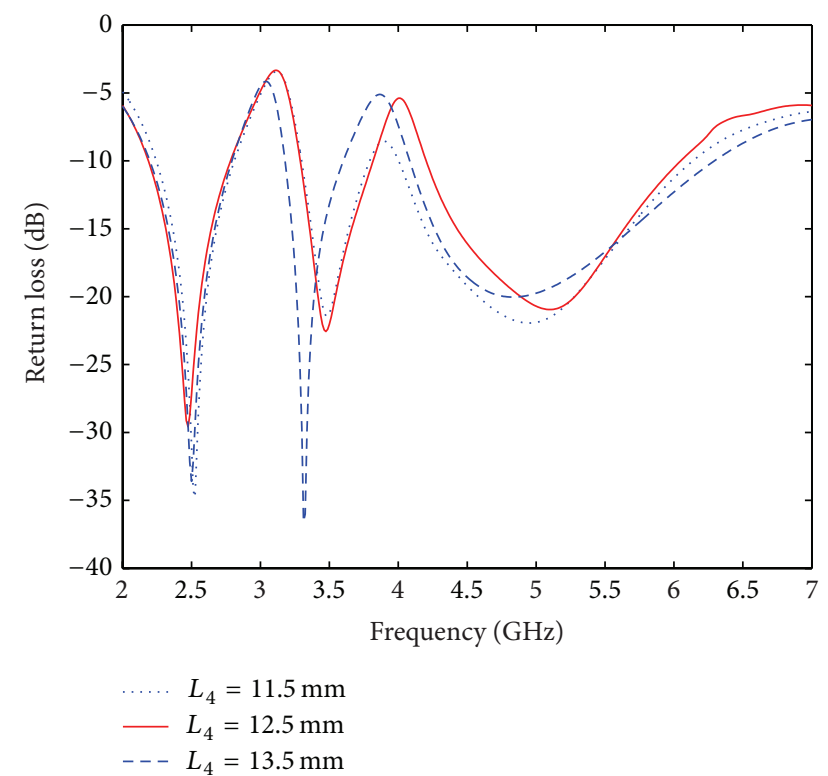

FIGURE 5: Simulated return loss of the proposed antenna with different values of two symmetric $L$ strips $\left(L_{4}\right)$. (Other parameters: $L_{1}=40.0 \mathrm{~mm} ; L_{2}=1.8 \mathrm{~mm} ; L_{3}=17.2 \mathrm{~mm} ; L_{5}=3.0 \mathrm{~mm} ;$ $L_{6}=9.0 \mathrm{~mm} ; L_{7}=16.0 \mathrm{~mm} ; W_{1}=27.0 \mathrm{~mm} ; W_{2}=2.0 \mathrm{~mm} ;$ $W_{3}=1.0 \mathrm{~mm} ; W_{4}=2.0 \mathrm{~mm} ; W_{5}=3.0 \mathrm{~mm} ; W_{6}=9.0 \mathrm{~mm} ;$ $W_{7}=17.0 \mathrm{~mm} ; W_{8}=1.0 \mathrm{~mm} ; W_{9}=8.5 \mathrm{~mm} ; W_{10}=2.0 \mathrm{~mm} ;$ $W_{11}=19.0 \mathrm{~mm}$; and $W_{12}=30.0 \mathrm{~mm}$.)

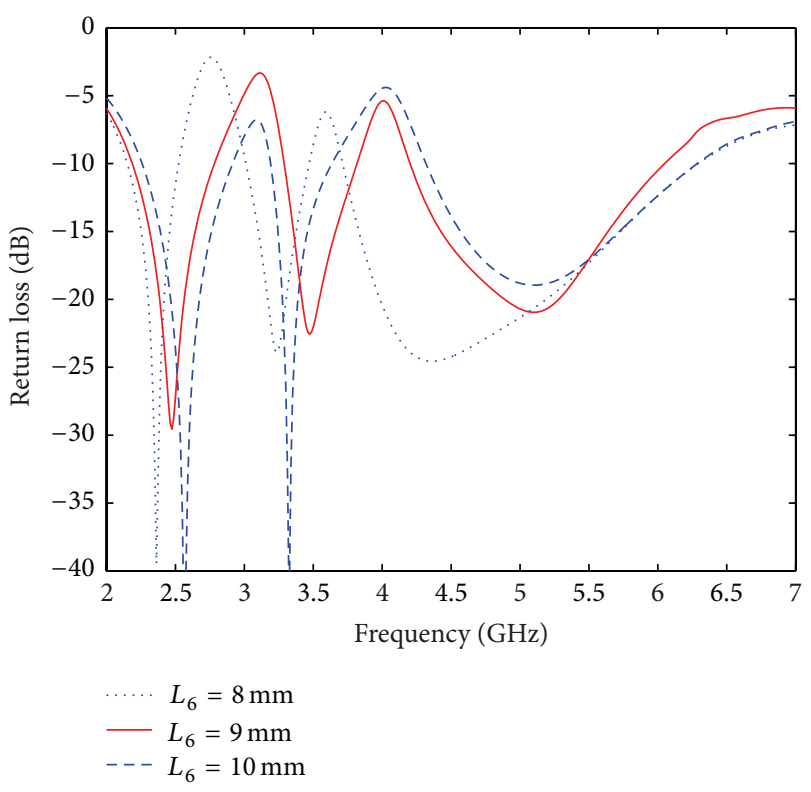

FIGURE 6: Simulated return loss of the proposed antenna with different values of two folded arms $\left(L_{6}\right)$. (Other parameters: $L_{1}=$ $40.0 \mathrm{~mm} ; L_{2}=1.8 \mathrm{~mm} ; L_{3}=17.2 \mathrm{~mm} ; L_{4}=12.5 \mathrm{~mm} ; L_{5}=$ $3.0 \mathrm{~mm} ; L_{7}=16.0 \mathrm{~mm} ; W_{1}=27.0 \mathrm{~mm} ; W_{2}=2.0 \mathrm{~mm} ; W_{3}=$ $1.0 \mathrm{~mm} ; W_{4}=2.0 \mathrm{~mm} ; W_{5}=3.0 \mathrm{~mm} ; W_{6}=9.0 \mathrm{~mm} ; W_{7}=17.0 \mathrm{~mm} ;$ $W_{8}=1.0 \mathrm{~mm} ; W_{9}=8.5 \mathrm{~mm} ; W_{10}=2.0 \mathrm{~mm} ; W_{11}=19.0 \mathrm{~mm}$; and $W_{12}=30.0 \mathrm{~mm}$.)

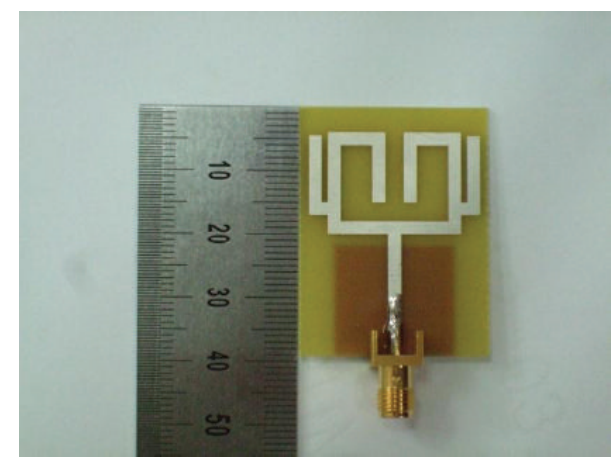

(a)

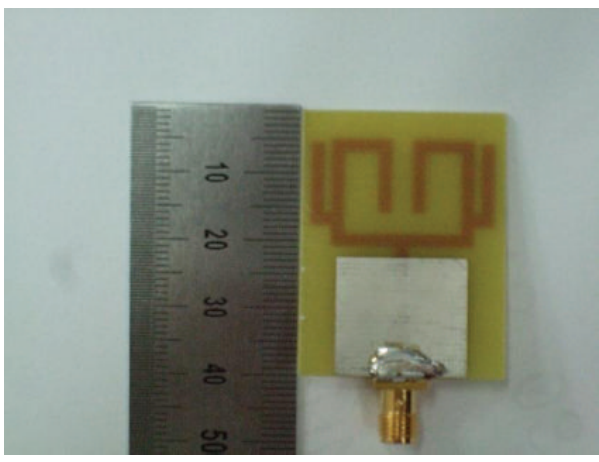

(b)

FIGURE 7: Prototype of the proposed dual-band antenna: (a) front view and (b) back view. 


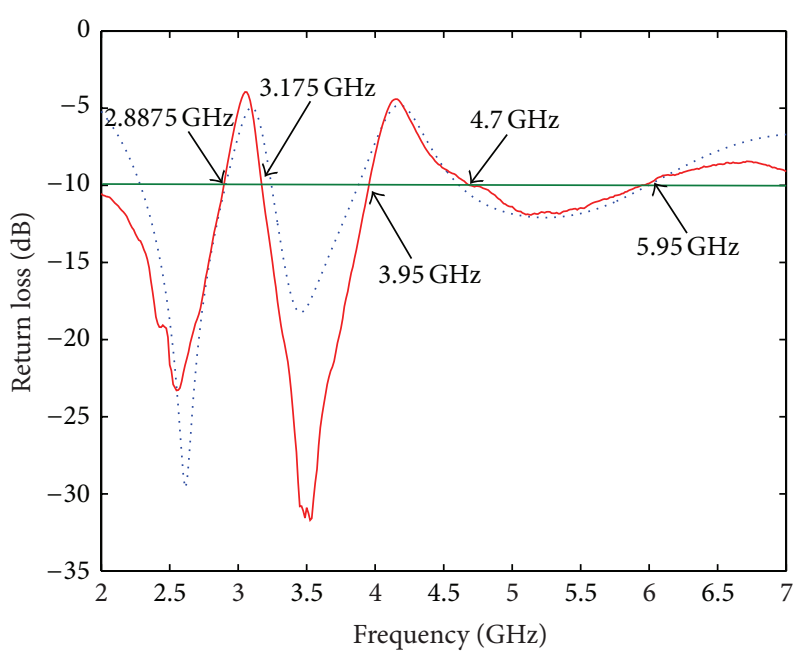

..... Simulation result

— Measurement result

FIGURE 8: Simulated and measured return loss versus frequencies of the proposed antenna.

and characteristics of the return loss slightly changed when $L_{4}$ changed from 11.5 to $13.5 \mathrm{~mm}$ in the 3.5 and $5 \mathrm{GHz}$ bands. It can also be seen in the figure, however, that the impedance bandwidth and characteristics of the return loss did not change in the $2 \mathrm{GHz}$ bands. This implied that the two symmetric $L$ strips are largely affected by the characteristics of the return loss in 3.5 and $5 \mathrm{GHz}$ bands. To design a good triple-band WLAN/WiMAX operation, $L_{4}$ was set at $12.5 \mathrm{~mm}$.

\subsection{Effect of Two Symmetric Folded Arms $\left(L_{6}\right)$. Figure 6} illustrates the return loss for the different values of the $L$ strips $\left(L_{6}\right)$. It can be seen in the figure that the impedance bandwidth and characteristics of the return loss slightly changed when $L_{6}$ changed from 8.0 to $10.0 \mathrm{~mm}$ in the required frequency bands. This implied that the two symmetric $L$ strips are highly affected by the characteristics of the return loss in the required frequency bands. To design a good triple-band WLAN/WiMAX operation, $L_{6}$ was set at $9.0 \mathrm{~mm}$.

The proposed antenna structure has several design parameters that can handle the resistance and reactance of the antenna input impedance. Therefore, the dimensions of the proposed antenna were set as follows: $L_{1}=40.0 \mathrm{~mm}$; $L_{2}=1.8 \mathrm{~mm} ; L_{3}=17.2 \mathrm{~mm} ; L_{4}=12.5 \mathrm{~mm} ; L_{5}=3.0 \mathrm{~mm}$; $L_{6}=9.0 \mathrm{~mm} ; L_{7}=16.0 \mathrm{~mm} ; W_{1}=27.0 \mathrm{~mm} ; W_{2}=$ $2.0 \mathrm{~mm} ; W_{3}=1.0 \mathrm{~mm} ; W_{4}=2.0 \mathrm{~mm} ; W_{5}=3.0 \mathrm{~mm}$; $W_{6}=9.0 \mathrm{~mm} ; W_{7}=17.0 \mathrm{~mm} ; W_{8}=1.0 \mathrm{~mm} ; W_{9}=$ $8.5 \mathrm{~mm} ; W_{10}=2.0 \mathrm{~mm} ; W_{11}=19.0 \mathrm{~mm} ; W_{12}=30.0 \mathrm{~mm}$; and $h=1.0 \mathrm{~mm}$. Based on the design dimensions, the proposed compact antenna was constructed and studied. A prototype of the proposed antenna was fabricated with the aforementioned design parameters and is shown in Figures 7 (a) and 7(b).

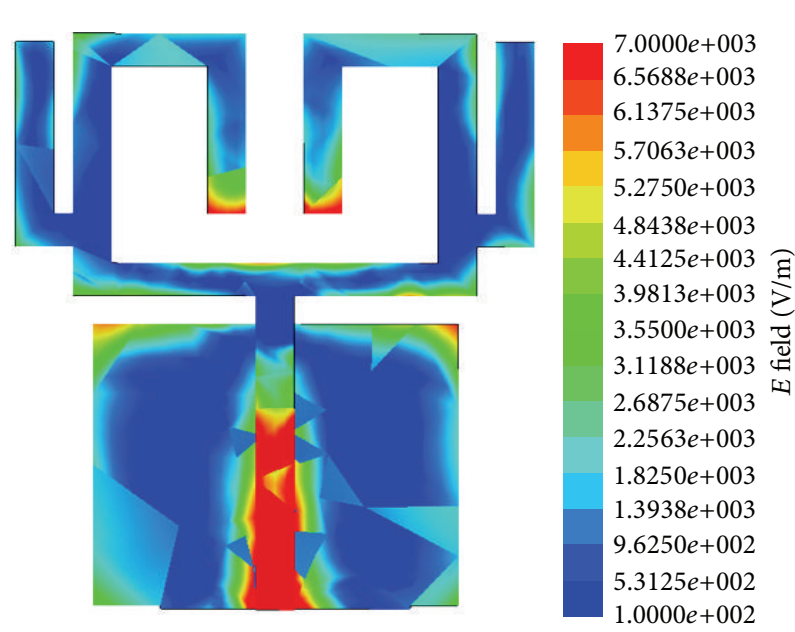

(a)

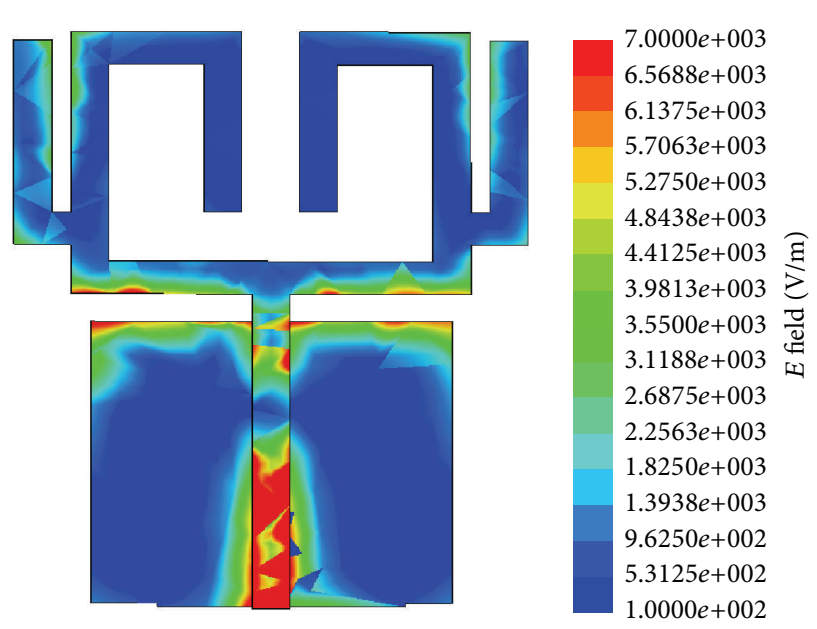

(b)

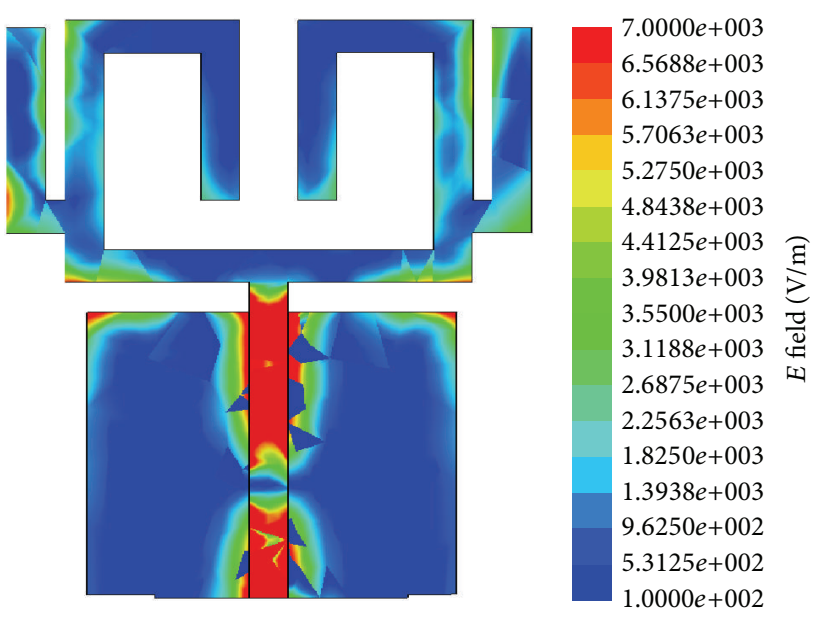

(c)

Figure 9: Surface current distributions at (a) $2.48 \mathrm{GHz}$, (b) $3.55 \mathrm{GHz}$, and (c) $5.06 \mathrm{GHz}$. 

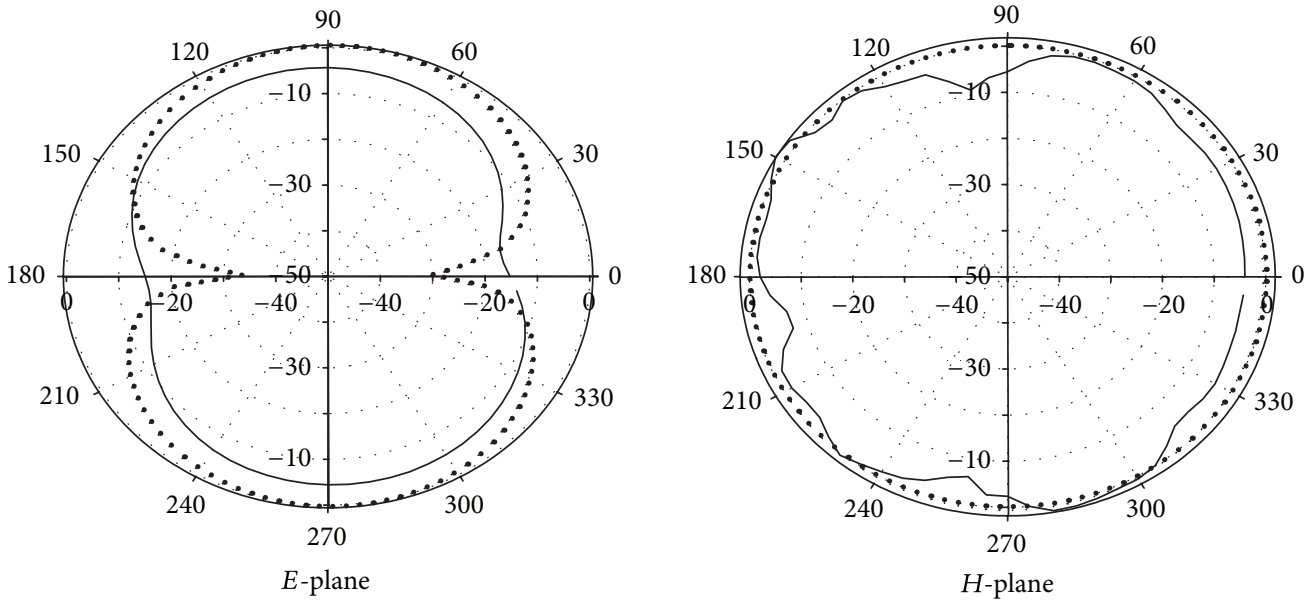

$$
\begin{array}{r}
\ldots \text { Simulated } \\
\ldots \text { Measured }
\end{array}
$$$$
\text { ... Simulated }
$$$$
\text { — Measured }
$$

(a)
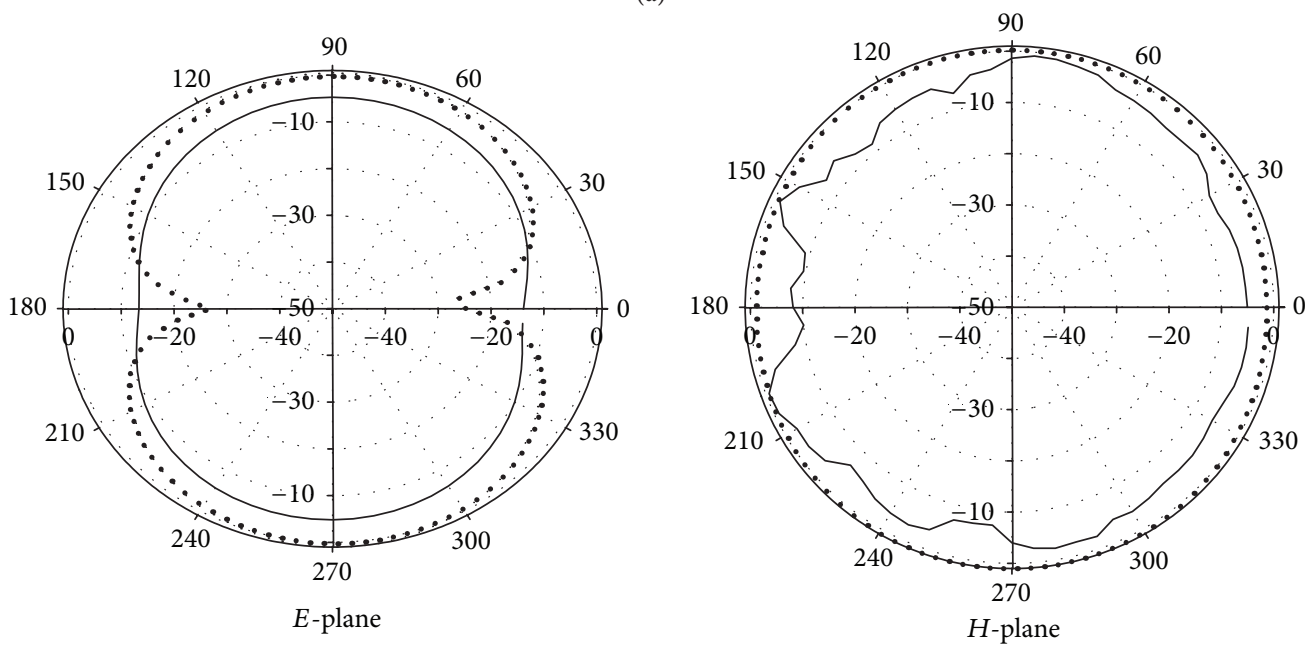

$\cdots$ Simulated
Measured

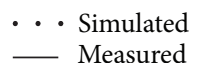

(b)
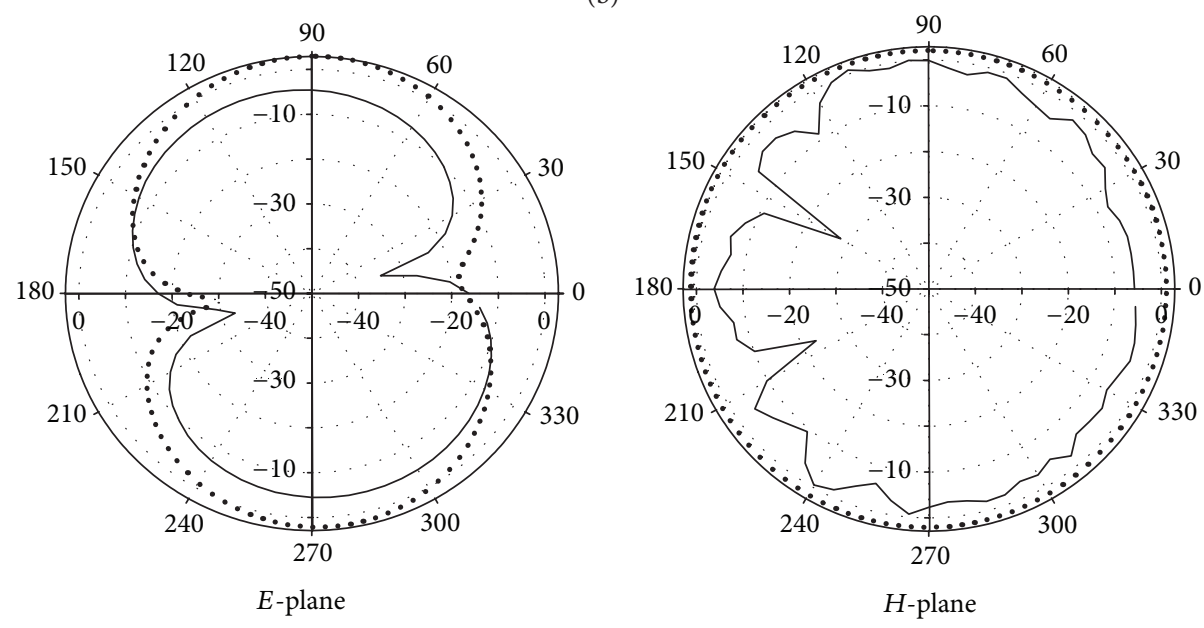

$\ldots$ Simulated

... Simulated

— Measured

(c)

Figure 10: Continued. 

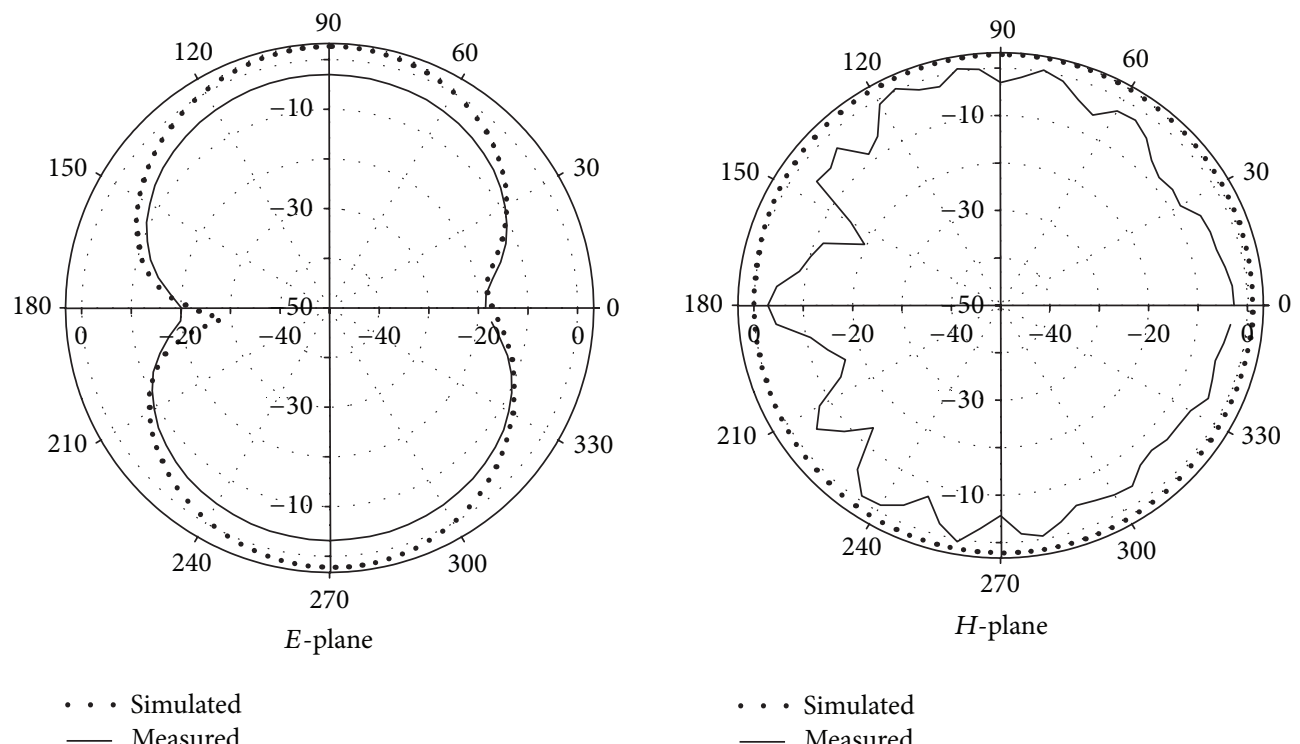

$\cdots$ Simulated
- Measured

— Measured

(d)

FIGURE 10: Radiation patterns of the proposed antenna for WLAN/WiMAX operation frequencies: in the (a) $2.5 \mathrm{GHz}$; (b) $3.5 \mathrm{GHz}$; (c) $5.3 \mathrm{GHz}$; and (d) $5.7 \mathrm{GHz}$ bands.

\section{Measurement}

Based on the detailed dimensions given in the previous section, a prototype for the proposed triple-band antenna was fabricated and measured. The measured results were performed by using an Anritsu MS4644A vector network analyzer in Silla University. The far-field radiation patterns and gains were measured by using a far-field anechoic absorber obtained from Foxconn Corporation in Republic of Korea. Figure 8 describes the simulated and experimental return loss against the frequency for the proposed antenna, where generally acceptable agreements between them have been achieved. Because the simulation used a waveguide port and an SMA connector was used for measurement, there is a difference between the measured and the simulated results. To confirm the accurate return loss characteristics for the designed antenna, it is recommended that the manufacturing and the measurement process must be performed more carefully. Based on the measured results, three relative impedance bandwidths, with $-10 \mathrm{~dB}$ return loss of about $887.5 \mathrm{MHz}(36.32 \%, 2,000-2,887.5 \mathrm{MHz}), 775 \mathrm{MHz}$ (21.75\%, 3,175-3,950 MHz), and 1,250 MHz (23.47\%, 4,700$5,950 \mathrm{MHz})$, respectively, can satisfy the typical bandwidth requirement for the $2.4-2.484$ and $5.15-5.825 \mathrm{GHz}$ WLAN bands, as well as $2.5-2.69,3.4-3.7$, and $5.25-5.85 \mathrm{GHz}$ WiMAX bands, respectively.

Theoretically, HFSS was used to evaluate and verify the three resonant frequencies $2.48,3.55$, and $5.06 \mathrm{GHz}$, which mainly depended on the lengths of the different current paths along the folded arms and $L$ strips. As expected, it was obvious that the different surface currents were excited by the 2.48 and $3.55 \mathrm{GHz}$ frequencies, respectively, through folded arms and $L$ strips. Figures 9(a), 9(b), and 9(c) show the surface current density excitations along the folded arms and $L$ strips in the cases of the three resonant frequencies, 2.48, 3.55, and 5.06 GHz, respectively. As shown in Figure 9(a), the lowest band surface current density excitations along the folded arms were observed when the resonant frequency was $2.48 \mathrm{GHz}$. As observed in the middle-band excitation in Figure 9(b), a larger surface current density flowing along the symmetric $L$ strips was observed when the resonant frequency was $3.55 \mathrm{GHz}$. As shown in Figure 9(c), however, larger surface current densities flowing not only along the folded arms but also along the $L$ strips were observed when the resonant frequency was $5.06 \mathrm{GHz}$. Thus, it is implied that the $5 \mathrm{GHz}$ band excitation is contributed by the radiations of the folded arms and the $L$ strips. Likewise, based on the current density of the proposed antenna, $L_{2}$, the gap length between the rectangular ring, open-ended antenna and the ground plane, and $W_{3}$, the gap width between the rectangular ring, open-ended antenna and the $L$ strip, strongly affect antenna performance in all required frequency bands. The required frequency response characteristics can be obtained by optimizing the values of $L_{2}$ and $W_{3}$.

Figure 10 shows the measured 2D far-field radiation patterns in the $E$-plane $(x-z$ plane $)$ and $H$ plane $(y-z$ plane). Figures $10(\mathrm{a}), 10(\mathrm{~b}), 10(\mathrm{c})$, and $10(\mathrm{~d})$ show the $2 \mathrm{D}$ radiation patterns at $2.5,3.5,5.3$, and $5.7 \mathrm{GHz}$, respectively. Good agreement is obtained between the simulated and measured results. Based on these radiation patterns, the proposed antenna displays nearly omnidirectional radiation characteristics in the $H$-plane and monopole-like radiation pattern characteristics in the $E$-plane at the considered frequencies. 


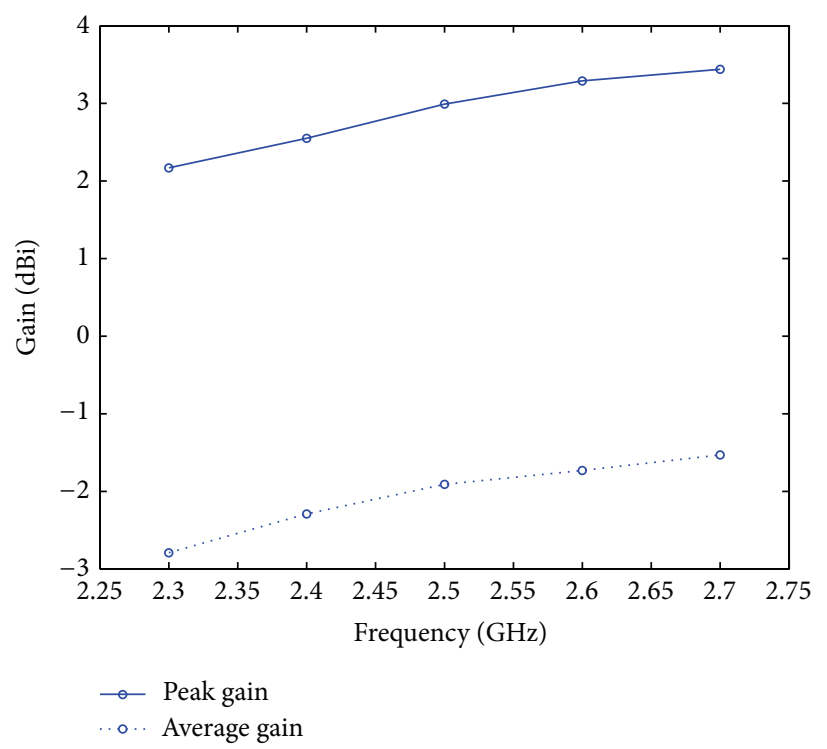

(a)

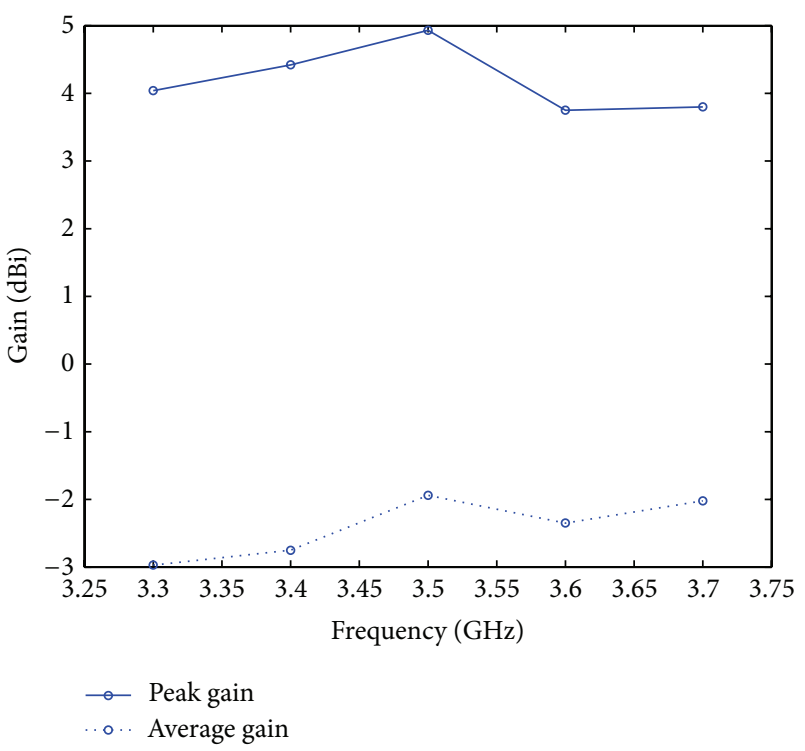

(b)

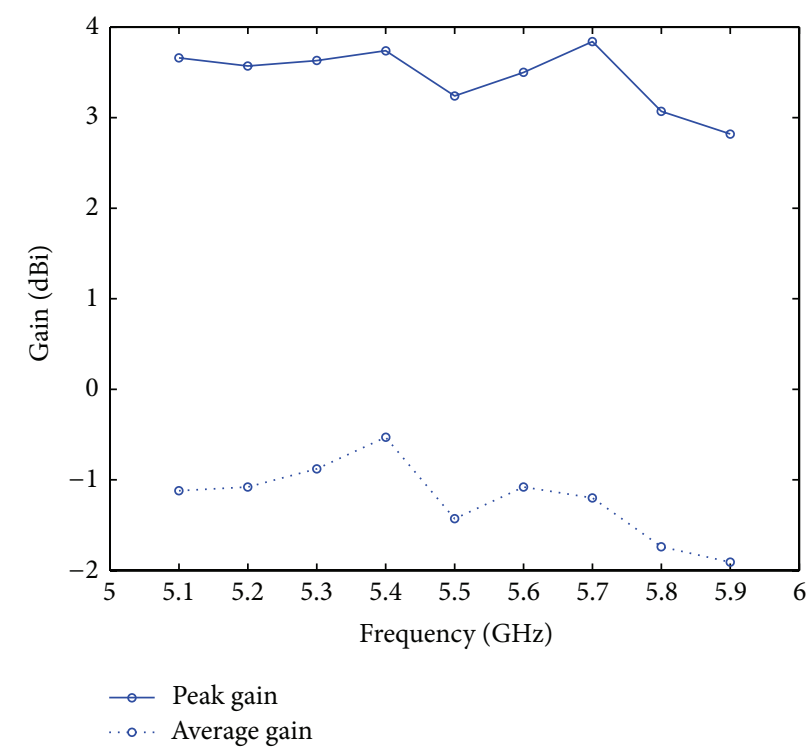

(c)

FIGURE 11: Measured antenna peak and average gains for the following operating frequencies: (a) $2.4 / 2.5 \mathrm{GHz}$ band, (b) $3.5 \mathrm{GHz}$ band, and (c) $5 \mathrm{GHz}$ band.

Figures 11(a), 11(b), and 11(c) show the 3D measured antenna peak and average gain for the frequencies across the 2.4/2.5, 3.5, and $5 \mathrm{GHz}$ bands. The $2.4 / 2.5 \mathrm{GHz}$ band had an antenna peak gain level of about 2.17 3.44 dBi (Figure 11(a)), and the $3.5 \mathrm{GHz}$ band about 3.75 4.93 dBi (Figure 11(b)). The measured antenna gain levels were about $3.57 \sim 3.74 \mathrm{dBi}$ in the $5.3 \mathrm{GHz}$ band and about $2.82 \sim 3.84 \mathrm{dBi}$ in the $5.8 \mathrm{GHz}$ band (Figure $11(\mathrm{c})$ ). The $2.4 / 2.5 \mathrm{GHz}$ band had an antenna average gain level of about $-2.79 \sim-1.53 \mathrm{dBi}$ (Figure 11(a)) and the $3.5 \mathrm{GHz}$ band about $-2.97 \sim-1.94 \mathrm{dBi}$ (Figure 11(b)). The measured antenna gain levels were about $-1.12 \sim-0.53 \mathrm{dBi}$ in the $5.2 \mathrm{GHz}$ band, and about $-1.91 \sim-1.08 \mathrm{dBi}$ in the $5.8 \mathrm{GHz}$ bands (Figure 11(c)). The 3D antenna gain had a peak value of
$2.99 \mathrm{dBi}$ at $2.5 \mathrm{GHz}$. At $3.5 \mathrm{GHz}$, the 3D maximum peak gain was $4.93 \mathrm{dBi}$; at $5.3 \mathrm{GHz}, 3.63 \mathrm{dBi}$; and at $5.8 \mathrm{GHz}, 3.07 \mathrm{dBi}$.

\section{Conclusion}

A rectangular ring, open-ended planar monopole antenna with two symmetric folded arms and $L$ strips for WLAN/WiMAX applications was proposed. By employing these structures, the proposed antenna can yield three different resonances to cover the desired bands while maintaining a simple structure. The results of the parametric studies on the proposed antenna were discussed. In particular, two folded arms and two symmetric $L$ strips 
depend heavily on the characteristics of the proposed antenna in the $2.4 / 2.5 \mathrm{GHz}$ band and $5 \mathrm{GHz}$ bands, respectively. Furthermore, the studies on surface current distributions of the operating frequencies were discussed. The measured results show that the obtained impedance bandwidths are $36.32 \%(2.0-2.89 \mathrm{GHz}), 21.75 \%(3.18-3.95 \mathrm{GHz})$, and about $23.47 \%(4.7-5.95 \mathrm{GHz})$, respectively, which are suitable for WLAN and WiMAX applications. In addition, the proposed antenna has good radiation characteristics and gains in the three operating bands, so it can emerge as an excellent candidate for multiband applications in wireless communication.

\section{Acknowledgments}

This research was financially supported by the Ministry of Education, Science, and Technology (MEST) and the National Research Foundation of Korea (NRF) through the Human Resource Training Project for Regional Innovation. Likewise, the authors would like to thank the Director S. G. Lee and Jeffrey Park, senior engineer at the R\&D Center of Foxconn Corporation in Korea, for the assistance in the measurement of antenna radiation patterns.

\section{References}

[1] "WorldWide Interoperability for microwave access forum or WiMAX forum," http://www.wimaxforum.org/.

[2] "IEEE 802.16 workinggroup on broadband wireless access standards," http://grouper.ieee.org/groups/802/16/index.html.

[3] C.-Y. Pan, C.-H. Huang, and T.-S. Horng, "A new printed Gshaped monopole antenna for dual-band wlan applications," Microwave and Optical Technology Letters, vol. 45, no. 4, pp. 295-297, 2005.

[4] J. H. Yoon, "Fabrication and measurement of rectangular ring with open-ended CPW-fed monopole antenna for 2.4/5.2-GHz WLAN operation," Microwave and Optical Technology Letters, vol. 48, no. 8, pp. 1480-1483, 2006.

[5] Y. Song, Y.-C. Jiao, H. Zhao, Z. Zhang, Z.-B. Weng, and F.S. Zhang, "Compact printed monopole antenna for multiband WLAN applications," Microwave and Optical Technology Letters, vol. 50, no. 2, pp. 365-367, 2008.

[6] Z. Zhang, Y. C. Jiao, Y. Song, T. L. Zhang, S. M. Ning, and F. S. Zhang, "A modified CPW-FED monopole antenna with very small ground for multiband WLAN applications," Microwave and Optical Technology Letters, vol. 52, no. 2, pp. 463-466, 2010.

[7] Z.-Y. Liu, Y.-Z. Yin, L.-H. Wen, W.-C. Xiao, Y. Wang, and S.-L. Zuo, "A Y-shaped tri-band monopole antenna with a parasitic M-strip for PCS and WLAN applications," Journal of Electromagnetic Waves and Applications, vol. 24, no. 8-9, pp. 1219-1227, 2010.

[8] S.-H. Yeh and K.-L. Wong, "Dual-band F-shaped monopole antenna for 2.4/5.2 GHz WLAN application," in Proceedings of the IEEE Antennas and Propagation Society International Symposium, pp. 72-75, San Antonio, Tex, USA, June 2002.

[9] Y.-L. Kuo and K.-L. Wong, "Printed double-T monopole antenna for 2.4/5.2 GHz dual-band WLAN operations," IEEE Transactions on Antennas and Propagation, vol. 51, no. 9, pp. 2187-2192, 2003.
[10] W. C. Liu, W. R. Chen, and C. M. Wu, "Printed double S-shaped monopole antenna for wideband and multiband operation of wireless communication," IEE Proceedings-Microwaves Antennas and Propagation, vol. 151, pp. 473-476, 2004.

[11] Q. Y. Zhang and Q. X. Chu, "Triple-band dual rectangular ring printed monopole antenna for WLAN/WiMAX applications," Microwave and Optical Technology Letters, vol. 51, no. 12, pp. 2845-2848, 2009.

[12] X. S. Ren, Y. Z. Yin, S. F. Zheng, S. L. Zuo, and B. W. Liu, “Tripleband rectangular ring monopole antenna for WLAN/WiMAX applications," Microwave and Optical Technology Letters, vol. 53, no. 5, pp. 974-978, 2011.

[13] X. Li, W. Hu, Y. F. Wang, X. W. Shi, and X. T. Gu, "Printed triple band rectangular ring monopole antenna with symmetrical $\mathrm{L}$ strips for WLAN/WiMAX applications," Microwave and Optical Technology Letters, vol. 54, pp. 1049-1052, 2012.

[14] B. Li, Z. H. Yan, and C. Wang, "Dual rectangular ring with open-ended CPW-fed monopole antenna for WLAN/WiMAX applications," Progress In Electromagnetics Research Letters, vol. 25, pp. 101-107, 2011.

[15] Y. F. Wang, B. H. Sun, K. He, R. H. Li, and Y. J. Wang, "A compact tri-band antenna for WLAN/WiMAX applications," Microwave and Optical Technology Letters, vol. 53, no. 10, pp. 2371-2375, 2011.

[16] Ansoft High Frequency Structure Simulator (HFSS) Version 10. 0, Ansoft Corporation, 2005. 

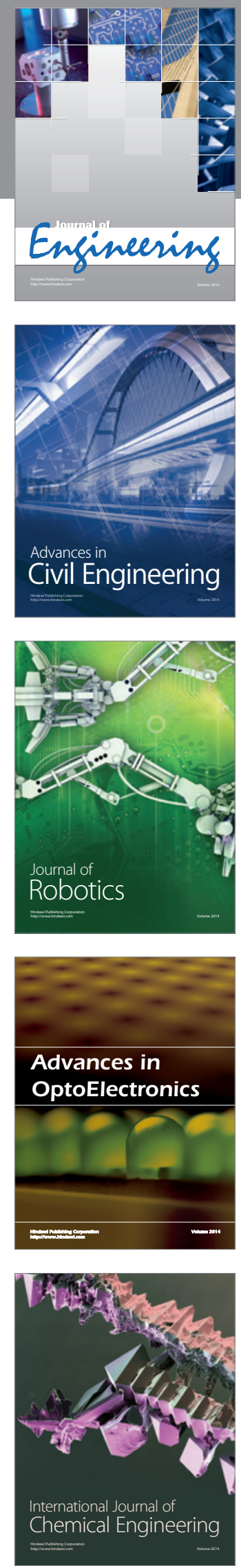

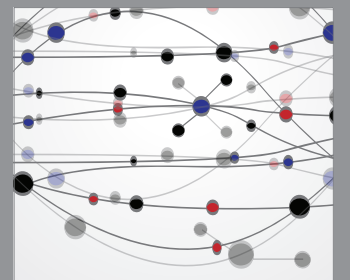

The Scientific World Journal
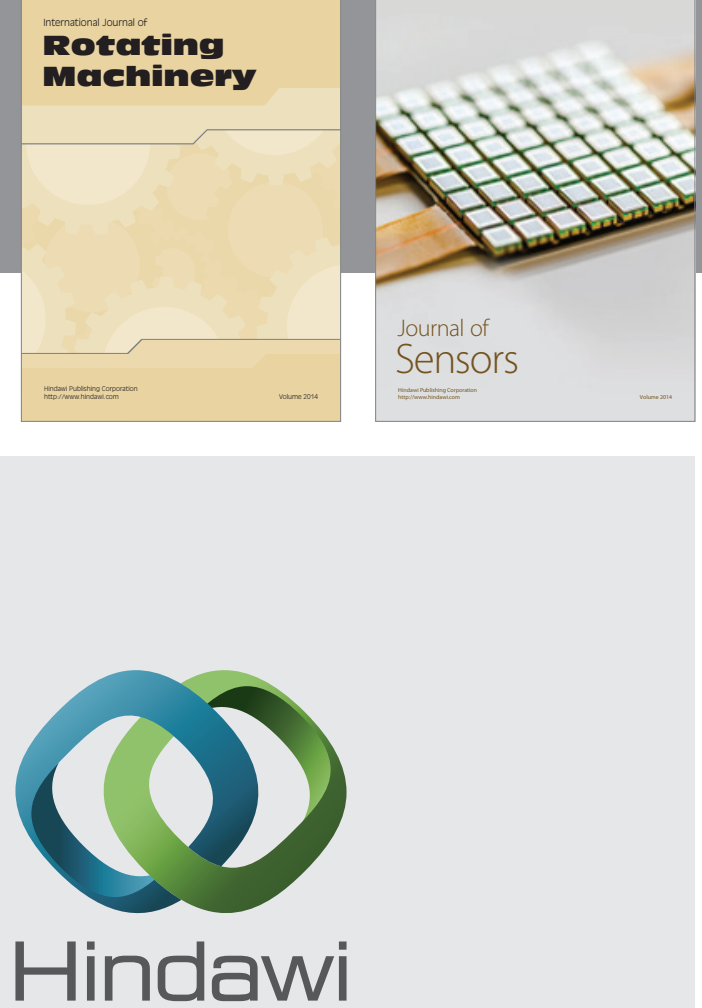

Submit your manuscripts at http://www.hindawi.com
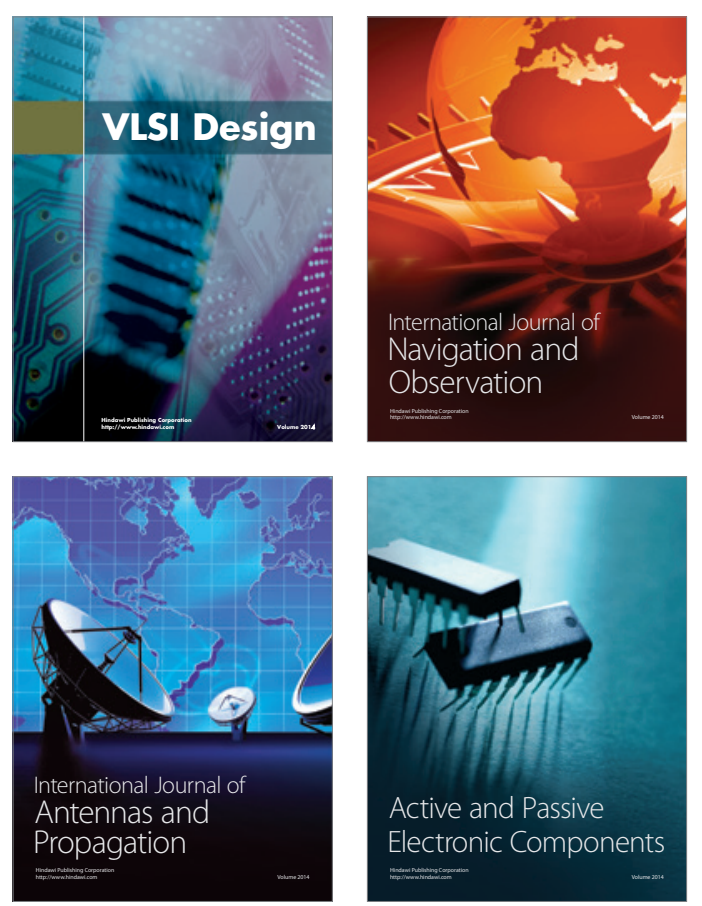
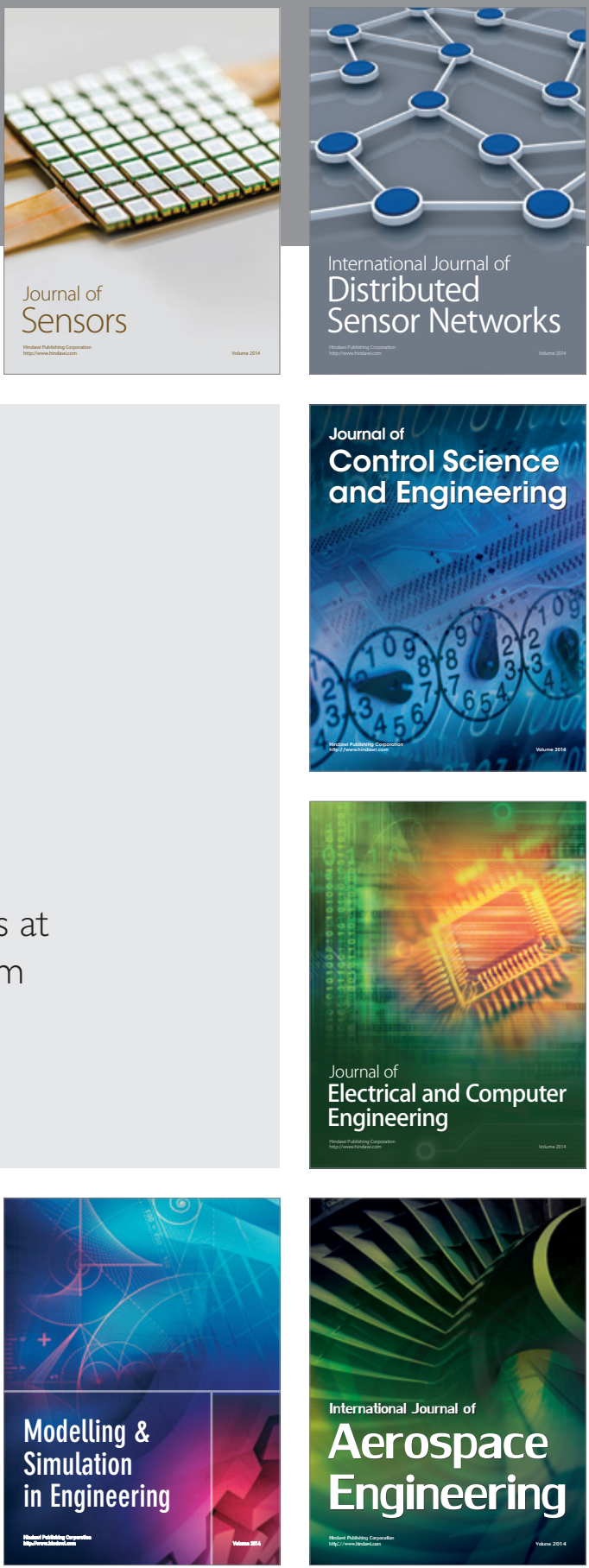

Journal of

Control Science

and Engineering
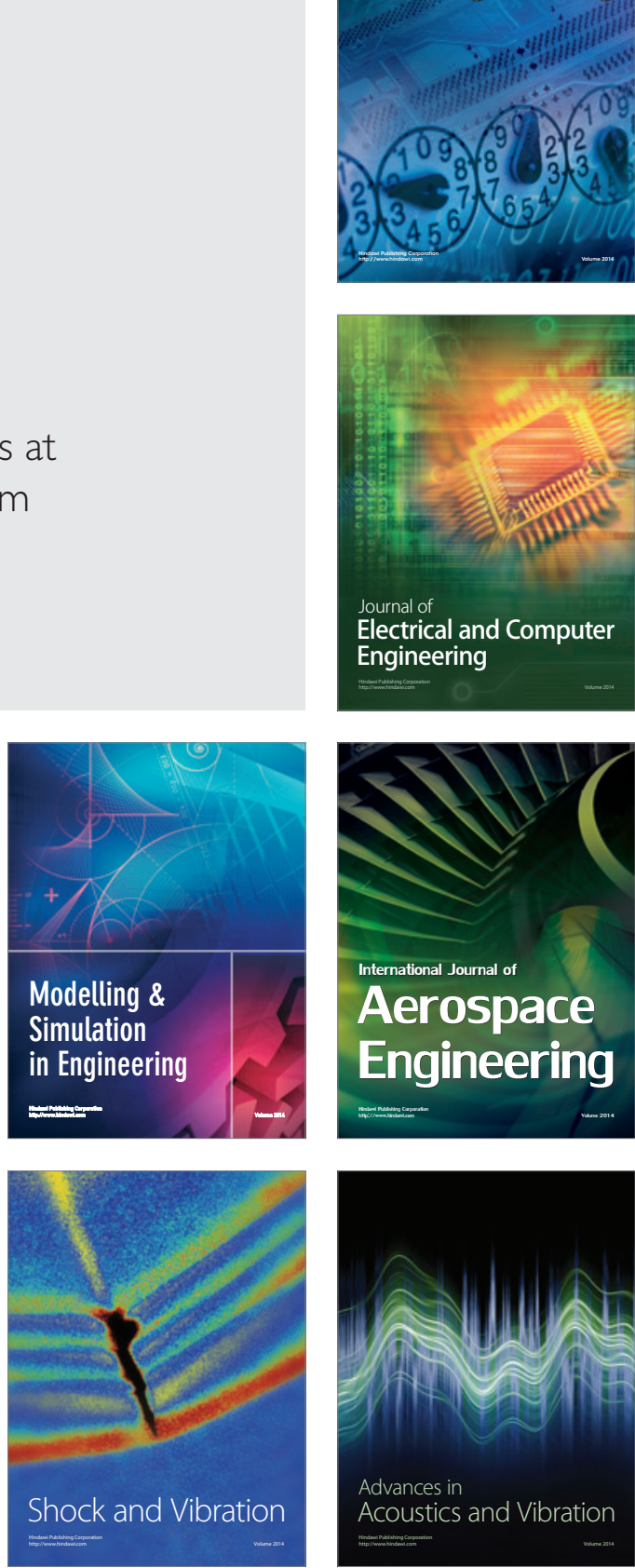